\title{
Integration of refugees at universities: Austria's more initiative
}

\section{Johann Bacher ${ }^{1} \cdot$ Elisabeth Fiorioli ${ }^{2} \cdot$ Robert Moosbrugger $^{1} \cdot$ Chigozie Nnebedum $^{1}$. Dimitri Prandner ${ }^{1} \cdot$ Nadine Shovakar $^{2}$}

Published online: 7 November 2019

(C) The Author(s) 2019

\begin{abstract}
The so-called refugee wave in the summer of 2015 led to an impressive wave of helpfulness in Austrian society. Universities Austria (uniko) - the umbrella organization of the 22 public universities in Austria - set up and launched an initiative called MORE. MORE provides refugees and asylum seekers with additional opportunities and perspectives that go beyond basic tools for survival. All 22 public universities implemented MORE, albeit in different ways. The article draws on a specific case - the MORE initiative - which aims to integrate refugee students into university life and higher education, as well as on data collected within the scope of evaluating the particular cases at hand. Analysis focuses on whether MORE has contributed to integrate refugee students. Drawing on different integration theories, the findings of this evaluation provide an insight as to how integration is achieved and affected by influencing factors such as personal characteristics, the usage of program elements, etc. Hence, the paper gives insight in the applicability of different integration theories and may be helpful for improving MORE or similar initiatives. The results confirmed the assumptions of modern sociological integration theories. Universities who offer the MORE program can conclude that they should take care of special, vulnerable groups, and that they should offer more than language classes in order to foster integration. Integration depends on the characteristics of the refugee group, the general societal and political climate, and on the specific attitudes towards the group in question.
\end{abstract}

Keywords Integration theories · Refugees · University $\cdot$ MORE initiative

Robert Moosbrugger robert.moosbrugger@jku.at

1 Institute of Sociology, Department of Empirical Social Research, Johannes Kepler University Linz, Altenberger Straße 69, 4040 Linz, Austria

2 uniko, Floragasse 7/7, 1040 Wien, Austria 


\section{Introduction}

The wave of refugees that reached Austria in the summer of 2015 had a profound impact on the small country, which has traditionally been seen as a foreign skeptic country (Ulram 2009; Prandner 2018). For example, as recently 25 years ago, the Freedom Party of Austria initiated an anti-immigrant referendum, titled Austria First. Despite considerable protests, the referendum was signed by more than 400,000 voters ( $7.96 \%$ of the electorate). Xenophobic attitudes are also reflected in available surveys. In the European Social Survey (ESS) 2002, for example, the balance of the opinion - whether the country is made a better or worse place to live in as a result of migration - was negative for Austria; in this regard, Austria differs from many other countries. In the ESS 2014, the balance has become even less supportive of foreigners, whereas other countries have moved towards a more positive balance (Heath and Richards 2016).

It is uncertain whether the events of 2015 resulted in a rise of right-wing populism and xenophobia (Bodlos and Plescia 2018). However, the arrival of refugees showed that large parts of Austrian civil society were willing to help in any way possible (Simsa 2017). Temporary shelters were quickly established, and Austrian citizens collected clothes and food and provided housing for refugees or engaged in volunteer work to take care of refugees (Meyer and Simsa 2018).

Over the summer of 2015, Universities Austria - an umbrella organization of the 22 public universities, without executive power-worked on a program to integrate refugees into university. In September 2015, the MORE initiative was officially launched, and by the end of 2015, all members had joined (uniko 2019). The idea of MORE is to offer refugees the possibility to participate in university life and in tertiary education. The MORE initiative provides refugees and asylum seekers with additional opportunities and perspectives beyond the provision of bare necessities such as food, accommodation, and medical help (Fiorioli 2017). The actual implementation fell within the responsibility of individual universities. Therefore, universities could, for example, determine whether they limit the number of places they offer to refugees; such limitations were mainly applied to additional (language) courses.

The helpfulness seen initially on the arrival of refugees has decreased in Austria in recent years. While civil society at large is still willing to help those in need, this has become noticeable among members of the public, and both the political narrative and societal climate regarding migration - and refugees in particular - has worsened drastically (Bacher 2017). Right-wing and populist parties rose to power, capitalizing on the population's fears (Verwiebe et al. 2018). This resulted in the so-called border protection and the enforcement of restrictive policies to minimize immigration (Bodlos and Plescia 2018).

Since regulations in nearly all fields of life have become more restrictive for MORE students, the MORE initiative is also indirectly affected by these changes. Nonetheless, refugees still arrive and stay in Austria, and the United Nations High Commissioner for Refugees (UNHCR) (2018) estimates that a total of 97,000 asylum seekers and beneficiaries with subsidiary protection were living in Austria in 2017, not including persons entitled to political asylum in 2016 and 2017, of which there were approximately 43,000. Therefore, integrating refugees, or at least offering possibilities to participate in parts of society during asylum procedure, remains a current issue. This need does not only result from demand, but from obligations to human rights and modern refugee law. As the European Convention on Human Rights (ECHR) (European Court of Human Rights 2018) states in Article 2 of the first Protocol: "No person shall be denied the right to education." As institutions committed to humanity, freedom, and rationality, universities therefore have a particular societal 
responsibility. According to the Austrian national strategy concerning widening participation of tertiary education, they are bound to expand broad participation and an integrative approach (Bundesministerium für Bildung, Wissenschaft und Forschung 2018, pp. 13, 55).

The article draws on a specific case - the MORE initiative - which aims to integrate refugee students into university life and higher education, as well as on data collected within the scope of evaluating the particular cases at hand. Analysis focusses on whether MORE has contributed to integrate refugee students. Drawing on different integration theories, the findings of this evaluation provide an insight as to how integration is achieved and affected by influencing factors such as personal characteristics, the usage of program elements, etc. Hence, the paper gives insight in the applicability of different integration theories and may be helpful for improving MORE or similar initiatives. "Initiatives for refugees in higher education and MORE in Austria" provides a short overview of initiatives aiming at integrating refugee students into higher education and describes the MORE initiative in greater detail; "Social integration of immigrants: the case of refugees" introduces the theoretical background; "Database: evaluation design of the MORE initiative" provides an overview of the evaluation design and the data collected; in "Results," the results are presented; "Summary and conclusions" summarizes the results and draws conclusions regarding influences on the integration of refugees into tertiary education and on designing programs intending to support this process.

\section{Initiatives for refugees in higher education and MORE in Austria}

With MORE, Austria offers a program that is one of many in Europe (for an overview of these programs, see Streitwieser et al. 2018; Eurydice 2019). Most initiatives are organized by either an international or a national organization or at the university level. One example of an international-level program is the DAFI program - the Albert Einstein German Academic Refugee Initiative - of the UNHCR, which nearly doubled its efforts in 2016 to help especially Syrian and Afghan refugees (UNHCR 2017, p. 7). On the national level, Eurydice (2019) reports that approximately 16 European countries mention large-scale measures to support the integration of refugees and asylum seekers into higher education. No such equivalent measures can be found in Spain, Switzerland, Finland, Hungary, Slovakia, the Baltic, and some Balkan countries or in some of the countries of the UK (Eurydice 2019, p. 15-17). Language training, grants, scholarships, as well as personal guidance, are the most common program foci. Germany offers all analyzed measures and is therefore quoted as an inspiring example. Streitwieser et al. (2018) also refer to numerous examples from Germany in their overview.

Other examples from Europe focus on legal or financial issues. In France, the French University Student Services Association offers funds and support for refugees trying to study in the country (Entraide Universitaire Française 2019). Similar approaches can be found in northern Europe. In Norway, the Refugee Education Post-Secondary Education (European Resettlement Network 2019) provides scholarships for young camp-refugees wishing to access college or university education, while Poland and Sweden have offered to waive tuition fees for refugees (Polish National Agency for Academic Exchange 2019; Swedish Council for Higher Education 2019). Nevertheless, in those countries in which no large-scale measures are mentioned, university-level initiatives are also made available: e.g. in Switzerland the blendedlearning program, InZone, from the University of Geneve (Streitwieser et al. 2018); and COMPAS in UK (Birkbeck University of London 2019), which offers tailored training for refugees to start an academic education. 
This short and incomplete overview shows that different initiatives for refugees have been implemented across Europe. Among the European initiatives, MORE stands out by being a nationwide offer made by a non-profit association. The results of this evaluation could provide further insight into how the European tertiary educational landscape may contribute to the integration of refugees and asylum seekers.

After the initial go-ahead by the rectorate, each university nominated MORE coordinators who were responsible for implementing the program at their university. Generally, interdepartmental teams set up the MORE program, which, in most cases, involved members from the rectorate, student admission service, international relations office, "language centers," and other university departments. The universities also cooperated with non-governmental organizations (NGO) who hosted the refugees and set up the initial contacts (such as Diakonie and Caritas who acted as official cooperation partners). In addition, Universities Austria found sponsors and defined certain support packages that were distributed to universities by certain criteria (uniko 2019).

The universities differ in their offerings to prospective students: some mainly offer German language classes; others allow refugees and asylum seekers to participate in special courses that are specifically conceptualized and tailored for refugees; and a third group of universities allows them to generally participate in lectures of different fields of study. In addition, universities provide "activities"- such as city walks and sports classes - aimed at fostering social interaction. All of these offerings are accompanied by a buddy program organized by the student union or by the coordinators of the MORE initiative.

The 22 public Austrian universities implemented the MORE initiative in different ways. Some universities decided to include all interested students who met the target group criteria; in other words, anyone able to prove that they are a refugee, asylum seeker, or beneficiary of subsidiary protection. Other universities developed individualized admissions procedures for the MORE program. At five universities, proof of a general qualification to study - equivalent to the Austrian Matura - is required to participate in MORE. Other ways to determine eligibility to participate in the courses include admissions interviews (at eight universities), language tests (at one university), personal consent given by instructors (at one university), or refugee accommodation supervisors (at one university). Some universities combine several of these procedures.

\section{Social integration of immigrants: the case of refugees}

One general objective of MORE is to contribute to the integration of refugees in Austrian society. Therefore, this section will give a short overview about sociological integration theories. In most cases, these theories concentrate on migration and immigrants, which differ regarding the cause of their migration: immigrants are persons who make a conscious decision to migrate to a foreign country with or without the intention of settling there, while refugees are coerced into moving from their home country. However, similarities also exist between these two groups: both immigrants and refugees face shocks in culture and language; both groups deserve security. Because of these similarities, sociological integration theories can also help to explain the integration of refugees. We will use the term "refugee" in a broad sense to include both asylum seekers and beneficiaries of subsidiary protection.

Esser's concept of integration was used as a theoretical starting point of the evaluation study (Esser 2001). Esser distinguishes between the integration of different parts of a system (system integration) and the integration of an individual in a larger (social) system, labelling the latter 
aspect "social integration." According to him, social integration covers four sub-dimensions: culturation, placement, interaction, and identification.

Culturation refers to the idea that immigrants or refugees must become familiar with the culture, norms, rules, and language of their host society. The acquisition of the language of the host society is seen as the key variable in this process. Placement refers to position within the host country's social structure, and participation in the labor market plays a central role within this dimension. Interaction includes contacts, friendships, and partnership with members of the host society. Finally, identification covers the emotional feeling of belongingness to the host society. According to Esser, a minimum requirement of identification is that the immigrants or refugees accept the constitution and political institutions of the host country. Esser maintains that those four dimensions are interwoven. However, in his theory, placement in the labor market and the acquisition of language - as prerequisites - play an important role in the integration process. In accordance with other integration theories, Esser distinguishes four types of integration on a theoretical level:

- Multiple integration - integration in the host society and in the society of origin,

- Assimilation - integration in the host society and disintegration in the society of origin,

- Segmentation - disintegration in the host society, but integration in the society of origin,

- Marginalization - disintegration in the host society and in the society of origin.

His theory is in line with the "straight line assimilation theories" in assuming that integration is only possible via assimilation. Assimilation theories and Esser's theory have been criticized by different authors, especially for the (implicit) assumption that assimilation is the only successful path towards integration. Critics claim that, on the one hand, other possible paths of integration exist, and that, on the other, assimilation does not automatically result in better living conditions for immigrants (Gans 1997; Lee 2009; Hans 2016).

For example, the concept of "segmented assimilation" describes one alternative successful path of immigration (Portes and Zhou 1993). Segmented assimilation implies that immigrants have a connection with host society as well to their society of origin, so that they can rely on resources and the social support of networks in both societies. With reference to the above typology, segmented assimilation corresponds to multiple integration. Lee (2009) maintained that, following the framework of segmented assimilation, immigrants tend to assimilate into one of the already-existing available social sectors, rather than adapting to one uniform host society; this is referred to as "minority culture of mobility" theory. It suggests that native minority groups are valuable assets for new immigrants of the ethnic group because they have the same culture, mentality, and characteristics (Neckerman et al. 1999) and that by assimilating into native minority groups, newly arrived immigrants feel protected from potential prejudice.

Other theorists maintain that new immigrants hardly disintegrate themselves from their home countries. This practice of reaching beyond the borders of their residence is what Heisler (2014) refers to as "transnationalism." Immigrants in this case are seen as members of two countries - the countries in which they reside and emigrated from. This indicates a flaw in the idea that assimilation is the path to a successful integration because many immigrants will opt for segmented assimilation.

Urry (2000) developed a more general critique; he claims that theories like Esser's have to overcome sedentarism and territorial nationalism (Sheller and Urry 2006). Refugees may only stay for a certain time in the host country before moving again, and that they may possess multiple identities. 
The societal values and biases of the host nation often do affect the integration of immigrants (Portes and Zhou 1993). Most immigrants move into a new environment that has different values to those of their home countries. They are seen as "strangers" (Ahmed 2000) facing detachment or even hostility. Assimilation into the new environment and segmentation from their home country becomes a Herculean task. Political, cultural, and societal climate - as well as the economic situation in host countries - are further aspects affecting especially straight-line or single-path assimilation. Such factors as government policies, the host country's societal values and biases, and the availability of ethnic communities already existing in the host community all play a great role in the overall process of integration.

The emphasis of the European Council on Refugees and Exiles (ECRE) on the dynamic nature of the integration of refugees, which it terms a "two-way process" (that is, it demands actions on the part of both the host and the immigrant), is valuable and crucial (ECRE 1999). A conducive atmosphere that is perceivable has to be provided by the host country for effective integration to take place, and the refugees' readiness to participate in society must be positive (Castles et al. 2002).

Studies on the integration of refugees support the assumptions of new integration theories but refer to specific problems. A study on the integration of refugees in London and Birmingham suggests that "bonded social networks" are needed for integration into the new environment (Atfield et al. 2007). Co-ethnic communities provide access to information and other resources and give new immigrants a sense of belonging. The study found some challenges with social bonding based on ethnicity. In some cases, new refugees distanced themselves from members of their own ethnic group due to different reasons (Strang and Ager 2010).

Morrice (2013) and Joyce et al. (2010), among others, highlight problems experienced by refugees at universities in particular. Those have no experiences concerning the educational system of the host country and differences in teaching styles, administrational structure, as well as assessment are not recognized by the universities and the heterogeneity within refugee groups is often ignored. Naidoo et al. (2018) argue for conceptualizing the process of integrating refugee students in new educational contexts must be seen as a holistic process resulting in an enabling culture building on assets of its addressees. When reviewing recent studies on the situation in Austria, Verwiebe et al. (2018) conclude that ties to localsvolunteers and others willing to seek exchanges with refugees - may open doors for refugees, as these ties open venues so that social capital can be generated in a Bourdieu-inspired sense. A key strategy for refugees to succeed in Austria therefore is tied to participation in activities that foster exchanges with the local population.

In summary, critics and the new concepts of integration stress the importance of considering different paths of integration, taking into account that integration might fail. Characteristics of the group of refugees, as well as those of the host society, are important factors that influence the path. Therefore, we will analyze whether the integration of refugees depends on their (group) characteristics, and will keep the political, societal, and cultural climate of the host society in mind when interpreting the results.

As already mentioned, the political narrative and societal climate of Austria has changed since 2015. Therefore, we expect that Syrian MORE students - who were the dominant group at the beginning of the refugee wave, from May 2015 until September 2015-had better chances and opportunities to integrate than groups arriving later. This is because they came in groups and were able to build on an ethnic network, they could integrate via segmented assimilation. In addition, Syrian MORE students were more likely to receive a positive asylum decision and hence were able to access more resources. Afghan students could also build on an 
ethnic network; however, they arrived later and so were confronted with more negative attitudes (Hajek and Stark 2017), more frequently receiving a negative asylum decision. Therefore, we expect these individuals to be less integrated compared with Syrian refugee students. Finally, we expect that all other MORE students have an unfavorable situation because they less frequently were able to rely on an existing ethnic network, and because they were more likely to arrive after 2015.

\section{Database: evaluation design of the MORE initiative}

The evaluation of MORE started in October 2017 and finished in October 2018. Following the direction of the literature on conducting evaluations (e.g., Rossi et al. 2001), we evaluated (1) demand, (2) implementation, and (3) outcome of the program. The evaluation used register data, a Web-based survey among MORE coordinators, and a survey among MORE students (see Table 1).

Universities Austria carried out the data collection and analysis for the register data and the online survey of the MORE coordinators under the direction of one of the authors of this paper. The Institute of Sociology at the University of Linz carried out the survey among the MORE students (Prandner and Moosbrugger 2018). Data were then collected from students enrolled in a particular course under the direction of two of the authors of this paper. A stepwise sampling procedure was applied. In a first step, a Web-based survey was offered. Due to a low response rate, in a second step, classroom interviews were carried out with MORE students at the three universities with most MORE students.

\section{Variables of interest for analyzing integration processes}

The number of MORE students and their socio-demographic characteristics provided information regarding the demand for the program, which is available via the MORE-RegisterData2018 and the MORE-Students-Survey2018 (see Table 1). Reported participation in and

Table 1 Design of the MORE initiative evaluation

\begin{tabular}{|c|c|c|}
\hline Data source & Sample characteristics & Main variables \\
\hline MORE-Register-Data2018 & $\begin{array}{l}\text { Target group: registered } \\
\text { MORE-students, winter term } \\
\text { 2015/2016 to winter term } \\
\text { 2017/2018 } \\
\text { Data collection: } 2018 \\
\text { Sample size: } N=2514\end{array}$ & $\begin{array}{l}\text { Number of students and } \\
\text { socio-demographic variables } \\
\text { Start of degree studies or a preparatory } \\
\text { study program }\end{array}$ \\
\hline MORE-Coordinator-Survey 2018 & $\begin{array}{l}\text { Target group: MORE coordinators } \\
\text { Data collection: } 2018 \\
\text { Sample size: } n=17\end{array}$ & $\begin{array}{l}\text { Goals of the university with the MORE } \\
\text { program, university admission } \\
\text { procedures, lessons learnt, and } \\
\text { outlook }\end{array}$ \\
\hline MORE-Student-Survey2018 & $\begin{array}{l}\text { Target group: all MORE students } \\
\quad \text { from winter term } 2015 / 16 \text { to } \\
\text { beginning of summer term } 2018 \\
\text { Survey mode: Web based and class } \\
\quad \text { room } \\
\text { Data collection: } 2018 \\
\text { Sample size: } n=124\end{array}$ & $\begin{array}{l}\text { Socio-demographic variables } \\
\text { Participation in and satisfaction with } \\
\text { different elements of MORE } \\
\text { initiative } \\
\text { Obtained German language level } \\
\text { Transition into the labor market and in } \\
\text { the educational system } \\
\text { Social interaction }\end{array}$ \\
\hline
\end{tabular}


satisfaction with different elements of the MORE program formed the basis for evaluating the program's implementation. This information was collected with the MORE-Students-Survey2018. The evaluation of the MORE program by the MORE coordinators provided additional information and deeper insights on implementation and usage.

Finally, three dimensions measured the outcome of the MORE initiative to integrate refugees in universities and in society: (1) German language competencies, (2) transition to the educational system and/or labor market (structural integration), and (3) social interaction. All three dimensions will be used to judge integration. The initiative will be considered successful if students reached B2 ${ }^{1}$ or a higher level in German proficiency, transited to the educational system and/or the labor market, and/or report an increase in social interaction.

MORE-Register-Data2018 provides information about the number of students who took up degree studies or preparatory study programs after being registered as MORE students (part of the second dimension of integration). However, MORE-RegisterData2018 only captures the start of an ordinary study programs at a public Austrian university. If, for example, a MORE student moves to a university of applied sciences, they would not be covered by the register. The MORE-Student-Survey2018 covers a broader spectrum of outcome variables, providing information on the German language level obtained (dimension 1), as well as their transition to an educational institution (university, university of applied sciences, pedagogical university, or apprenticeship) and into the labor market (dimension 2). Social interaction (dimension 3) determines whether MORE, in an evaluative sense leads to increased social interaction; more friends from Austria and other countries suggesting multiple integration, and more friends mainly from Austria suggesting assimilation.

\section{Data analysis and limitations}

IBM-SPSS Version 23.0 was used to analyze the data. A simple random sample of $n=124$ cases was assumed to calculate a 95\% confidence interval for the MORE-Students-Survey2018. The model of a simple random sample does not perfectly fit to the data-gathering process, though it does fit the first step of the online survey. The second step corresponds to a cluster sample of three universities. Cluster samples generally result in larger confidence intervals. However, the sample is drawn from a small population, which decreases the range of the confidence intervals. Considering both factors (increasing confidence with a cluster and decreasing it with a small population), the assumption of a simple random sample is an acceptable approximation. A 5\% error level was used for significance testing. Path models were used to link the group characteristics of the MORE students, program participation, and the outcome.

The study has several limitations, which were taken into account when interpreting the results, such as its cross-sectional design and the absence of causal inferences regarding the control group limit. It might be the case, for example, that a different program results in the same output or outperforms the program in question. Therefore, the results of our path analysis should be read cautiously. Additionally, the path model assumes a causal order of variables,

\footnotetext{
${ }^{1}$ According to the Common European Framework of Reference for Languages: Learning, Teaching, Assessment (Council of Europe 2018) B2-level implies that a user can "understand the main ideas of complex text...", is able to "interact with a degree of fluency and spontaneity..." and "can produce clear, detailed text on a wide range of subjects...."
} 
and that language competencies precede transition to educational systems or the labor market. More likely is the assumption that a simultaneous causal relation exists, and that integration into the labor market or educational system integration accords with increasing language competencies. However, a certain level of language competence must be reached before participation in one of the two systems is enabled.

Additionally, social interaction is only superficially measured; respondents were asked whether they had found additional friends by participating in MORE. This question allows us to evaluate the success of the MORE initiative, but it only covers a small aspect of respondent interaction.

Furthermore, the results of this study are based on a sample with unit nonresponse, which might bias the study results. In particular, it can be assumed that the survey did not reach successful students who had transmitted into the labor market as much because their contact information may no longer have been valid. In contrast, it is plausible that successful students who transited to regular studies participated more in the survey. As a consequence, transition into the labor market is likely to be underestimated, whereas transition into the educational system is likely to be overestimated. Finally, we were unable to test the influence of context factors - such as political and public climate - in a statistical way via multi-level modeling because data is only available for particular moments; we can only use them as a kind of background variable for interpretation.

\section{Results}

\section{Demand for the program: number of students and socio-demography of MORE students}

The number of MORE students underlines the demand for the program. In the 2015/16 winter term, 664 MORE students participated in the program. This number increased to over 1000 students in the 2016 summer term before decreasing (see Fig. 1). The registered numbers underestimate the actual demand because some universities implemented an application and acceptance procedure, consequently, not all students who wanted to enter the program could do so.

According to the register data, the average age of MORE participants was 26, and almost $90 \%$ were male. The most prominent countries of origin were Syria and Afghanistan, followed by Iraq and Iran. With an average age of 28.5, participants in the MOREStudents-Survey 2018 were slightly older than registered-data students. Larger differences were found according to gender, and females $(25.5 \pm 7.7 \%)$ were overrepresented in the survey. This was due to the sampling procedure and because females more frequently attended German courses, which build the frame of the second sampling step (see above). More than half the respondents stated that they arrived in Austria in 2015; one third arrived in 2016 or later, and only every tenth respondent stated that they arrived in Austria before 2015. About 28\% of respondents reported a positive asylum status (asylum or subsidiary protection had been granted). Almost three out of four students did not have an asylum status at the time the survey was conducted (asylum procedure was still in progress or their application had been declined) and, therefore, their prospects for staying in Austria were uncertain though they being in Austria for an average of 2 years and 5 months. 


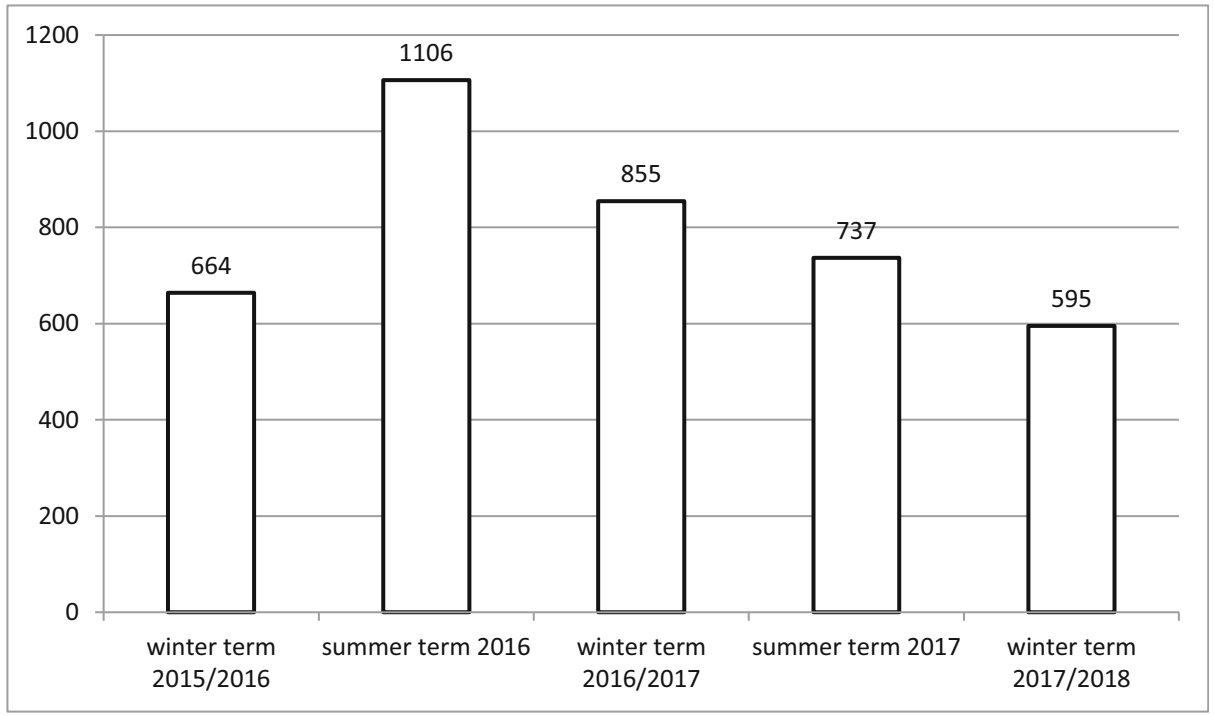

Fig. 1 Number of MORE students. Source: MORE-Register-Data2018 (Hochschulstatistik-BMBWF), calculations by the authors

\section{Evaluation of implementation}

Of those MORE students who responded to the survey (see Fig. 2), $85 \%$ had attended German language courses within the MORE program. Building up language skills is one of the main pillars of the MORE initiative and a necessary pre-condition for a transition into regular studies. An additional 15\% attended other courses, such as regular scientific lectures or art classes. Overall, 21\% participated in MORE activities. Twenty-one percent of the respondents were involved in the buddy program, where refugees and regular students pair for mutual support and meetups.

The survey revealed that MORE students were very satisfied with elements of the program. When evaluating different aspects from 1 to 4 , where 4 stands for "very satisfied" and 1 stands for "not satisfied at all", students typically gave responses close to 4 for language courses, the other courses, and the activities within MORE. Respondents also reported a slightly lower satisfaction, though one still indicating that they were "very satisfied," regarding their buddies (see Fig. 2).

As mentioned above, the MORE program was set up in different ways at the various universities involved. This was because there was a need to react quickly, and because solutions had to be found through interdepartmental cooperation-as well as cooperation with external organizations such as NGOs - to reach the target group. In this scenario, MORE coordinators played a crucial role in connecting all the players. In the survey, coordinators were asked whether they thought that admission criteria placed students correctly. More than half the respondents (seven out of 12) reported that they strongly or tended to agree that the students have been placed in the right courses. However, two coordinators disagreed strongly, giving no reason for their response. These diverging results may be explained by the fact that there were different, or in some cases absent, academic selection criteria. 


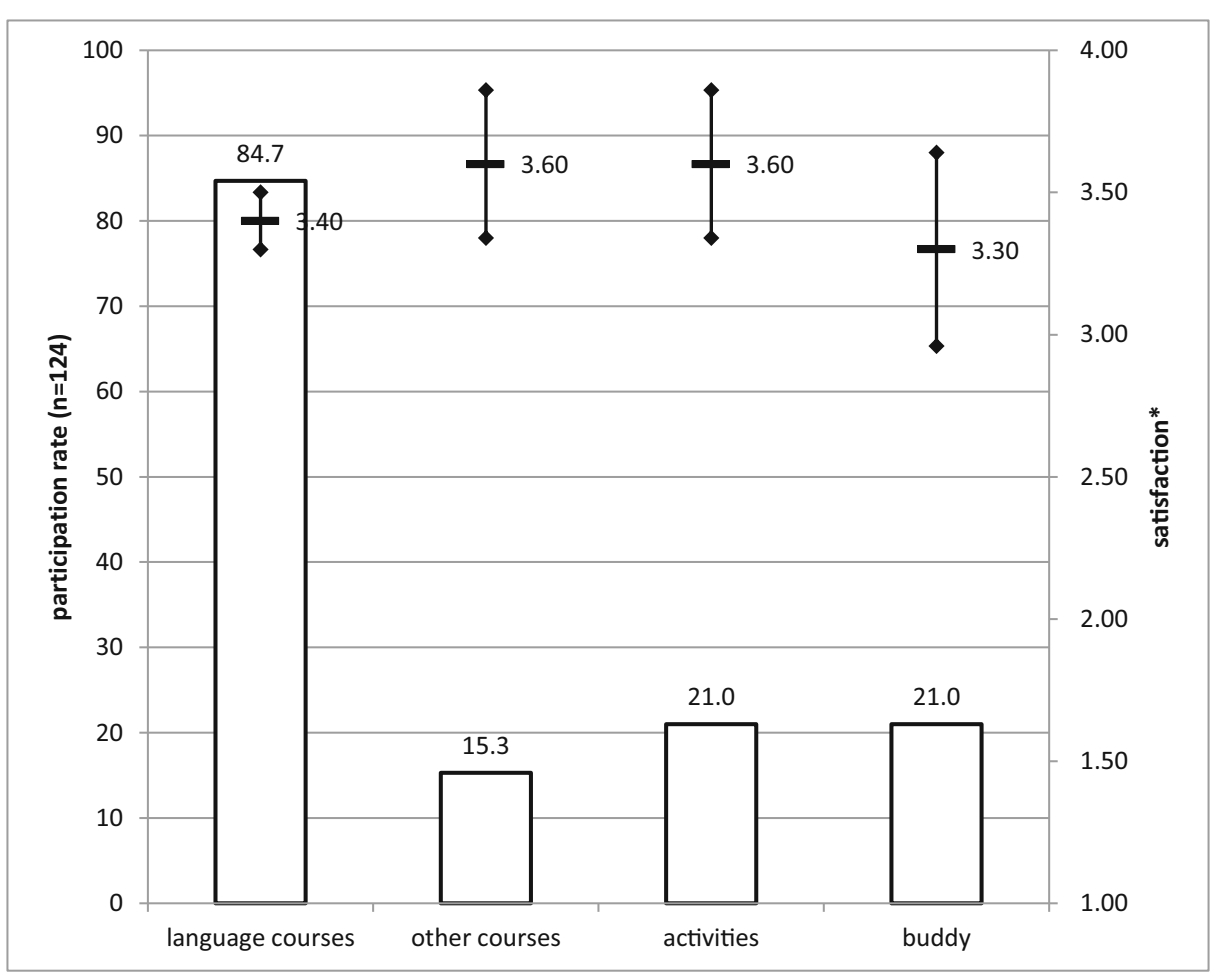

Fig. 2 Participation in and satisfaction with different elements of MORE by MORE students; asterisk, mean over five items (except buddy: mean over four items); range, 1-4; $1=$ not satisfied at all; $4=$ very satisfied

Overall, the MORE coordinators reported that they experienced MORE students as having enriched Austrian universities; one MORE coordinator mentioned that it helped their university move away from Euro-centrism. The respondents also experienced consequences of positive or negative outcomes of the asylum-granting process directly and reported being emotionally affected by it. Coordinators mentioned that they wanted to continue with the program since demand for it remained. Regarding the MORE program's sustainability and further development, measures promoting the advancement of women's, asylum seekers', and refugees' transitions to degree studies were recommended.

\section{Evaluation of outcome}

Overall, $38 \%$ of students referred to a language level of B2 or higher, and had therefore already reached a proficiency level that enabled them to understand complex situations, interact fluently and spontaneously with native speakers, and to produce written text (see "Evaluation of implementation"). The longer students had participated in MORE, the better their selfreported language skills were. ${ }^{2}$ MORE therefore provided a prerequisite for social integration according to assimilation theories.

\footnotetext{
${ }^{2}$ Pearson Correlation was 0.183 between attended semesters and self-assessed German language proficiency $(p=0.063)$.
} 
According to MORE-Register-Data2018, 60 MORE students passed over to a degree program between the 2015/2016 winter term and the 2017/2018 winter term, while 52 passed over to a university preparation program. A continuous increase in transitions took place, from 37 cases in the 2016 summer term, to 40 in the 2017 summer term (for degree programs: from 17 to 32 cases). This was due to the fact that preparation was required before achieving an appropriate language level $(\mathrm{C} 1$ of the Common European Framework of Reference for Languages CEFRL) and, where necessary, passing qualification exams for specific majors or subjects. Accordingly, it can be inferred that for future semesters a greater number of MORE students will begin their degree studies. With reference to these 2514 MORE students, the transition rate $(4.5 \%)$ was low. However, it should be considered that some MORE students took part only for one or two semesters and had to leave the MORE program for different reasons (see above). Considering only those individuals who stayed for more than one semester in the program, the transition rate was $10.2 \%$.

This rate is still lower than the rate calculated on the basis of the survey data (see Fig. 3). The MORE-Students-Survey2018 results in a transition rate of $17.7 \%$ (regular degree study programs) with a $95 \%$ confidence interval ranging from 10.8 to $24.6 \%$. As mentioned above, it may be assumed that the transition into education has been overestimated due to the datacollection approach. Another $6.5 \%$ of respondents reported being in a preparation program for regular degree studies.

Figure 3 illustrates that transition to degree or non-degree fields of study is only one outcome of the program. MORE students can move to preparatory studies within universities, or they can move to other educational systems (24.2\% moved in this way); they can also become employed. Overall, $14.4 \%$ of former MORE students reported that they were regularly employed or self-employed. In total, the survey revealed a success rate between $27 \%$ (confidence interval: $\pm 7.8 \%)$ to $37( \pm 8.5)$; the $37 \%$ success rate also included those who moved to another educational program or to apprenticeship. ${ }^{3}$

Regarding the different kinds of social interaction, multiple interaction-which corresponds to segmented assimilation - was the most frequent type. Overall, 46\% of students reported that the number of friends they had from Austria and other countries increased due to MORE, while $17 \%$ reported that the number of Austrian friends they had increased (assimilation). Accordingly, 63\% of MORE students reported increased social interaction with individuals from the host country. However, one in four students stated that they had only gained new friends from other countries, while $13 \%$ reported that they had found no new additional friends through MORE.

To gain insight into the process of social integration and the effects of the different elements of the MORE program, we ran an explorative path analysis (see Fig. 4). Gender and age, as well as uncertain asylum status and country of origin, were considered as exogenous variables. According to new integration theories (see part 3), the path model assumes that these variables have an effect on the endogenous variables in the model. The attendance of additional educational opportunities (other courses at the university, MORE activities, buddy system); achieved language skills; participation in the labor market; participation in tertiary education; and increased multiple social interaction, or at least assimilation, built the endogenous variables.

\footnotetext{
${ }^{3} n$ for total success rates are lower than the sum of different occupations as some respondents reported more than one occupation - that is, they studied and worked part time.
} 


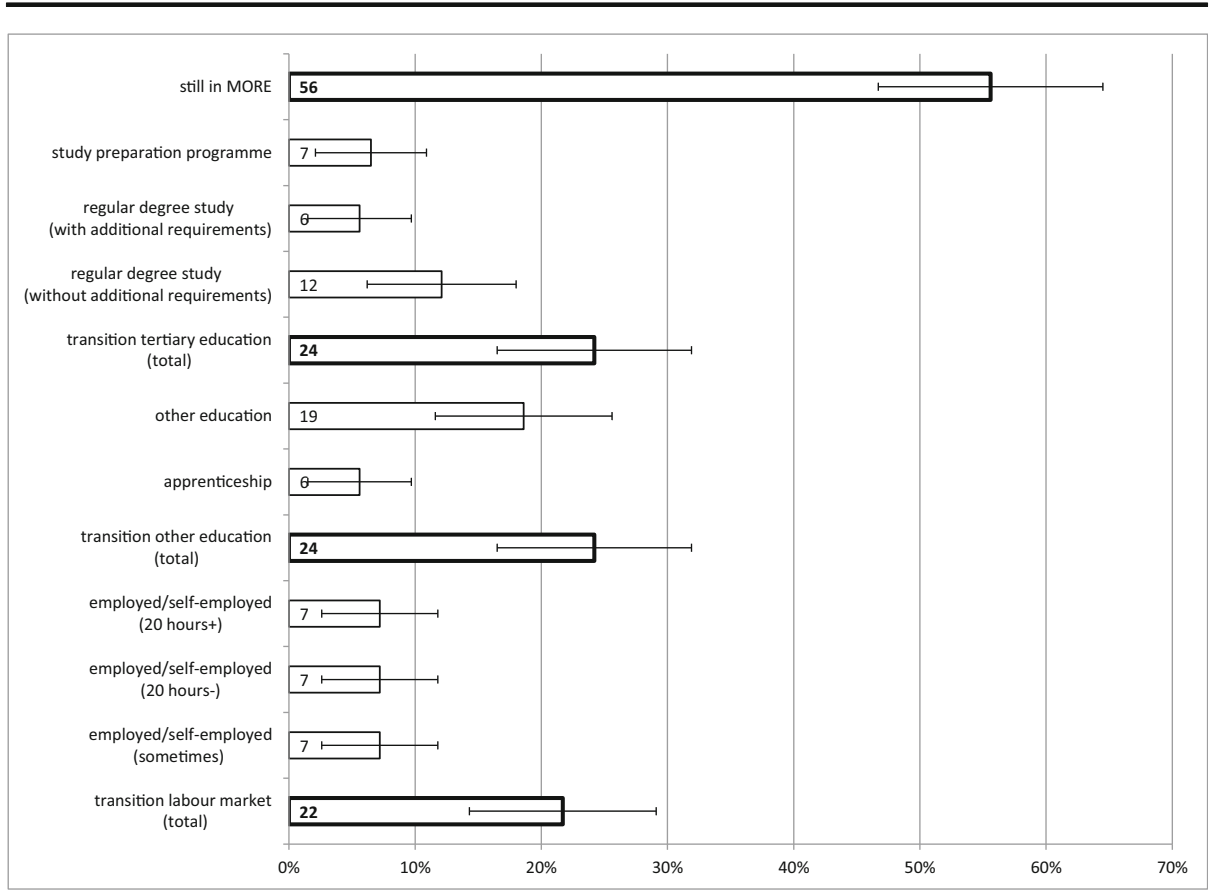

Fig. 3 Main occupation of MORE students. Source: MORE-Student-Survey2018, multiple responses, $n=124$

Attending additional educational opportunities, language skills, and the analyzed aspects of integration did not depend on age. While on the one hand, age can be regarded as an indicator of disruption of educational carriers (see "Social integration of immigrants: the case of

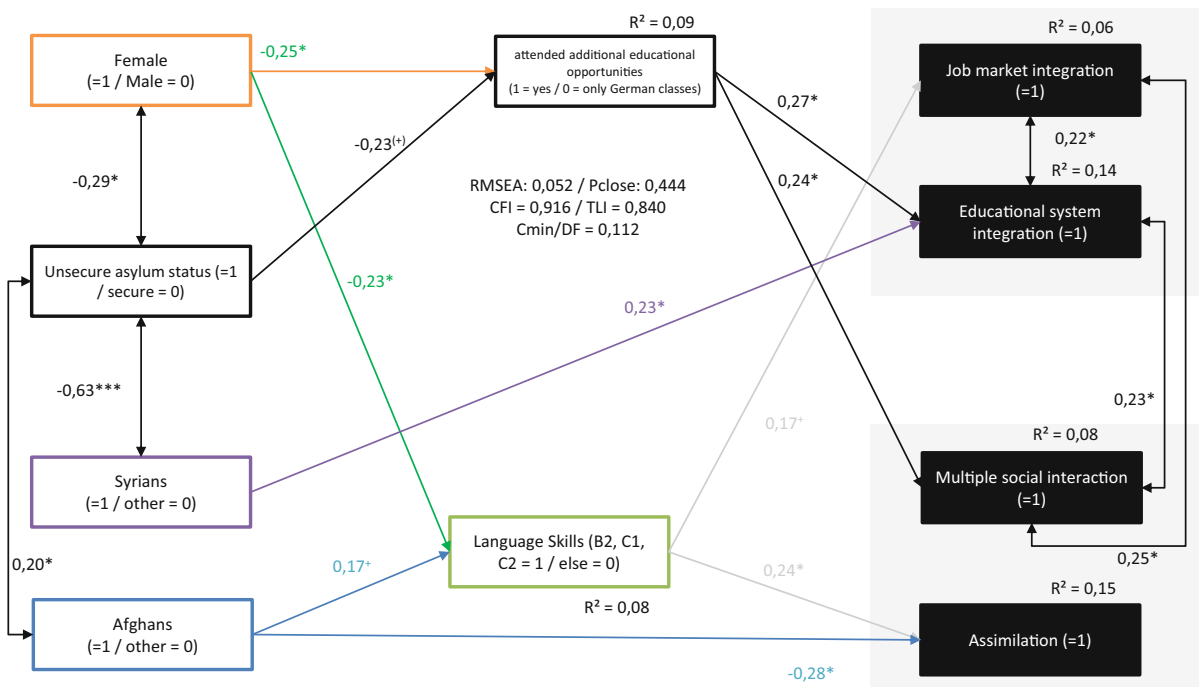

Fig. 4 Exploratory path analysis results. Standardized regression weights. Source: MORE-Students-Survey 2018, calculation by the authors using AMOS 25; estimation maximum likelihood, means estimated for missing data; $* * * p<0.001 ; * p<0.05 ;{ }^{+} p<0.1 ;{ }^{(+)} p<0.1$ but absolute value of effect larger than 0.20 
refugees"), on the other age relates to experience, the effects of which seem to cancel out. Among the other exogenous variables, the model revealed the following effects:

- Females were found to attend only German classes and possessed lower language skills. We can only speculate about the reasons for this: perhaps female students started later; were more isolated, had less contact with German speaking students, etc. However, the results must be seen from the perspective that female students with refugee backgrounds comprise a particularly vulnerable group (Naidoo et al. 2015).

- Refugees with an uncertain asylum status less often attended additional educational opportunities within MORE. This finding can be interpreted in two ways: this group of students had fewer opportunities to attend other courses (due to very restricted financial situations, poor accommodation availability, etc.), or these students concentrated on German language proficiency in order to increase, in their opinion, their chances of receiving a positive asylum decision.

- Syrian MORE students differed from other MORE students and more often reported having moved into the education system. This finding can be explained by different factors: first, Syrian students could rely on community networks of other Syrian refugeestudents who helped them orient themselves within the educational system; second, they more frequently came from urban areas and therefore experienced smaller cultural differences; third, they more often had a secure asylum status, which implies that they had equal chances to those of Austrian students; and, fourth a higher proportion of them arrived earlier in the first phase of the wave of refugees and therefore benefitted from the less restrictive climate at the beginning of the recent refugee "wave".

- Afghan MORE students reported better language skills and lower levels of assimilation. However, Afghans were unable to enter the labor market and educational system as frequently as other refugees. This must be seen in consideration of these students' backgrounds in that Afghanistan is a more rural country, and one that has experienced war for many years. In addition, Afghan students on average arrived later than other refugees and so were confronted with a more negative societal and political climate. Additionally, Afghans face stronger prejudices as compared with those of people from other countries (Hajek and Stark 2017).

Within the endogenous variables, path analyses discovered the following effects:

- The attendance of additional educational opportunities within MORE increased transition into the educational system and diversified the social interaction of MORE students.

- Language skills had a positive effect on assimilation (by increasing interactions with Austrians). However, assimilation did not correlate with participation in the labor market and the educational system.

- An additional German language effect on labor market integration is found when effects with an error level of $p<0.10$ are included. Hence, language is helpful for entering the labor market.

- Multiple social interactions positively correlated with integration into the labor market and the educational system. This causal relation may work in both directions. Integration into the labor market and the educational system fosters contacts with Austrians and people from other countries and vice versa - contacts with Austrians help to integrate refugees into the labor market and the educational system. 
In summary, the findings support modern sociological integration theories; assimilation and language competencies per se do not guarantee integration in subsystems of the society. Therefore, the critics of straightforward assimilation theory seem to be correct. Language skills play a certain role in integration though other paths are also available. In our case, language skills were found to lead to assimilation - a type of social interaction - which is not interrelated with other indicators for integration. In accordance with modern sociological integration theories, integration seems to be easier for some groups. This is especially true for MORE students originating from Syria — students who can rely on a network of their home community at university perform better.

\section{Summary and conclusions}

As a reaction to the so-called refugee wave of 2015, Universities Austria started the MORE program for refugees. The main idea of MORE was to offer refugees possibilities to participate in university life and in tertiary education and also to contribute to their integration into Austrian society. All 22 public Austrian universities participate in the MORE initiative; however, they implemented the program in different ways. Some universities opened their programs to all refugees regardless of their status and educational background, whereas others used a more selective application process. Since 2015, the climate towards refugees has become more restrictive in Austria as compared with other countries. This was one reason to evaluate MORE.

Modern sociological integration theories guided the evaluation. These new theories go beyond straight-line assimilation theories in assuming that different paths of integration are possible, and that assimilation does not necessarily result in successful integration. Characteristics of the group of refugees on the one hand, and those of the host society on the other, are regarded as key variables influencing integration.

The evaluation addresses three issues: the demand for the program, the implementation, and the output. Generated data within the evaluation not only facilitates judgment as to whether the program was successful, but also provides a glimpse into how integration as a whole works for different groups. Drawing on different integration theories, the findings of the evaluation provide an insight as to how integration is achieved and affected by influencing factors such as personal characteristics, the usage of program elements, etc.

The number of MORE students and their socio-demographic characteristics were used as indicators of demand. The program started with more than 600 participants in the first 2015/ 2016 winter term. This number then increased to more than 1000 for the following summer term. In the 2018/2019 winter term, about 500 MORE students participated in the program, with about $50 \%$ of these having been in the program for at least two semesters. Regarding implementation, four offerings were analyzed: German classes, other courses, MORE activities, and activities with buddies. Most students reported participation in German classes. The participation rates reported for the other offerings were lower. Students also reported high satisfaction with the various elements.

Output was measured according to three dimensions of integration: acquisition of the German language; participation in the educational system and labor markets; and, following the logic of evaluation, increased interaction with members of the host society and with persons from other countries, including the country of origin. 
About $38 \%$ of MORE students reported attaining a German level of B2 or above and, according to the register data, $10 \%$ left MORE in order to enroll in a regular study program at a public university. The survey data revealed a higher transition rate because the survey covered transitions to other educational institutions as well as to the labor market. According to the survey, $22 \%$ of MORE students moved to the labor market. Approximately the same percentage moved to the educational system.

Finally, a path analysis supports modern sociological integration theories. Integration depends on the characteristics of the refugee group, the general societal and political climate, and on the specific attitudes towards the group in question. In addition, the analysis showed that language skills and assimilation do not result in a higher transition rate to the educational system.

Our analyses and results have several limitations, and further research is required. Nonetheless, the study allows some general conclusions to be drawn, conclusions that will be helpful for improving the MORE program and for other, similar initiatives intending to foster integration of refugee students:

- First, although the number of refugees has decreased in the last year, need and demand still exist for the MORE program and/or similar programs, albeit reduced. Need results from obligation of human rights, demand from the number of students. For example, nearly 500 students are still in the program, and MORE coordinators also expressed their willingness to continue the program.

- Second, it is important to take better care of groups for whom integration is more difficult. Three disadvantaged groups can be identified within the MORE program: females; refugees without recourse to an ethnic community, such as those hailing from African countries; and students whose asylum status is uncertain.

- Third, it is insufficient to offer only German classes. To foster integration, it is necessary to offer a broader program and to motivate students to participate in other elements of that program.

Finally, it should be stressed that the success of the MORE program and similar programs depends on the political and societal climate, and on legal regulations; both have become more restrictive in many countries in recent years so that integration programs on a meso-level are faced with more difficulties. The societal great challenge is to accelerate the refugees' transition to the educational system or to the labor market.

Funding Information Open access funding provided by Johannes Kepler University Linz.

Open Access This article is distributed under the terms of the Creative Commons Attribution 4.0 International License (http://creativecommons.org/licenses/by/4.0/), which permits unrestricted use, distribution, and reproduction in any medium, provided you give appropriate credit to the original author(s) and the source, provide a link to the Creative Commons license, and indicate if changes were made.

\section{References}

Ahmed, S. (2000). Strange encounters. Embodied others in Post-Coloniality. London: Routledge.

Atfield, G., Brahmbhatt, K., \& O'Toole, T. (2007). Refugees' experiences of integration. Birmingham: Refugee Council and University of Birmingham. 
Bacher, J. (2017). Polarisierungstendenzen in Österreich? Ergebnisse einer latenten Klassenanalyse der Einstellungen zur Immigration. In F. Altenburg, A. Faustmann, T. Pfeffer, \& I. Skrivanek (Eds.), Migration und Globalisierung in Zeiten des Umbruchs. Festschrift für Gudrun Biffl (pp. 379-397). Krems: Edition Donau-Universität Krems.

Birkbeck University of London (Ed.). (2019). Compass project. London: Birkbeck.

Bodlos, A., \& Plescia, C. (2018). The 2017 Austrian snap election: A shift rightward. West European Politics, 41(6), 1354-1363. https://doi.org/10.1080/01402382.2018.1429057.

Bundesministerium für Bildung, \& Wissenschaft und Forschung. (2018). Universitätsbericht > 2017. Wien: BMBWF.

Castles, S., Korac, M., Vasta, E., \& Vertovec, S. (2002). Integration: Mapping the field. Home Office online report 29/03. London: Home Office.

Council of Europe. (2018). Common European framework of reference for languages (CEFR). https://www.coe. int/en/web/common-european-framework-reference-languages.

ECRE. (1999). Good practice guide on the integration of refugee in the European Union. Brussels: ECRE.

Entraide Universitaire Française (Ed.). (2019). Les étudiants réfugiés francophones. Paris: Entraide Universitaire Française (EUF).

Esser, H. (2001). Integration und ethnische Schichtung. MZES Arbeitspapiere 40. Mannheim: Mannheimer Zentrum für Europäische Sozialforschung.

European Court of Human Rights. (2018). European convention on human rights. Strasbourg: Council of Europe.

European Resettlement Network. (2019). Supporting refugees access higher education.

Eurydice. (2019). Integrating asylum seekers and refugees into higher education in Europe. National policies and measures. Luxembourg: Publications Office of the European Union.

Fiorioli, E. (2017). Hochschulbildungsangebote für Geflüchtete. In S. Binder \& G. Fartacek (Eds.), Facetten von Flucht aus dem Nahen und Mittleren Osten (Kultur- und Sozialanthropologie) (1st ed.). Wien: Facultas.

Gans, H. J. (1997). Toward a reconciliation of 'assimilation' and 'pluralism': The interplay of acculturation and ethnic retention. International Migration Review, 31(4), 875. https://doi.org/10.2307/2547417.

Hajek, P., \& Stark, J. (2017). Integrationsbarometer 2/2017 Integrationsbefragung. Wien: Österreichischer Integrationsfonds.

Hans, S. (2016). Theorien der Integration von Migranten-Stand und Entwicklung. In H. U. Brinkmann \& M. Sauer (Eds.), Einwanderungsgesellschaft Deutschland (pp. 23-50). Wiesbaden: Springer Fachmedien Wiesbaden.

Heath, A., \& Richards, L. (2016). Attitudes towards immigration and their Antecendents. Topline results from round 7 of the European social survey. ESS Topline Results, (7). https://www.europeansocialsurvey. org/docs/findings/ESS7_toplines_issue_7_immigration.pdf.

Heisler, B. (2014). The sociology of immigration: From assimilation to segmented integration, from the American experience to the global arena. In C. B. Brettell \& J. F. Hollifield (Eds.), Migration theory (p. 77). Routledge.

Joyce, A., Earnest, J., de Mori, G., \& Silvagni, G. (2010). The experiences of students from refugee backgrounds at universities in Australia: Reflections on the social, emotional and practical challenges. Journal of Refugee Studies, 23(1), 82-97.

Lee, C. (2009). Sociological theories of immigration: Pathways to integration for U.S. immigrants. Journal of Human Behavior in the Social Environment, 19(6), 730-744. https://doi.org/10.1080/10911350902910906.

Meyer, M., \& Simsa, R. (2018). Organizing the unexpected: How civil society organizations dealt with the refugee crisis. Voluntas: International Journal of Voluntary and Nonprofit Organizations, 29(6), 1159-1175. https://doi.org/10.1007/s11266-018-00050-y.

Morrice, L. (2013). Refugees in higher education: Boundaries of belonging and recognition, stigma and exclusion. International Journal of Lifelong Learning, 32(5), 652-668.

Naidoo, L., Wilkinson, J., Langat, K., Adoniou, M., Cunneen, R., \& Bolger, D. (2015). Case study report: Supporting school-university pathways for refugee students' access and participation in tertiary education. Kingswood: Western Sydney University.

Naidoo, L., Wilkinson, J., Adoniou, M., \& Langat, K. (2018). Refugee background students transitioning into higher education. Navigation complex spaces. Singapore: Springer Nature.

Neckerman, K. M., Carter, P., \& Lee, J. (1999). Segmented assimilation and minority cultures of mobility. Ethnic and Racial Studies, 22(6), 945-965. https://doi.org/10.1080/014198799329198.

Polish National Agency for Academic Exchange. (2019). . http://go-poland.pl/define-your-status. Accessed 25 July 2019.

Portes, A., \& Zhou, M. (1993). The new second generation: Segmented assimilation and its variants. The Annals of the American Academy of Political and Social Science, 530(1), 74-96. https://doi.org/10.1177 /0002716293530001006. 
Prandner, D. (2018). Diskursive Kläranlagen. In K. Mitschka \& K. Unterberger (Eds.), Public Open Space. Zur Zukunft öffentlich-rechtlicher Medien: 55 Beiträge aus österreichischer und internationaler Wissenschaft zur Medienzukunft (1st ed., pp. 84-86). Wien: facultas.

Prandner, D., \& Moosbrugger, R. (2018). Tertiary education opportunities for refugees: MORE-experiences and insights (SUF edition), Wien.

Rossi, P. H., Freeman, H. E., \& Lipsey, M. W. (2001). Evaluation. A systematic approach (6. edn., 4. Print). Thousand Oaks: SAGE.

Sheller, M., \& Urry, J. (2006). The new mobilities paradigm. Environment and Planning, 38, $207-226$.

Simsa, R. (2017). Leaving emergency management in the refugee crisis to civil society? The case of Austria. Journal of Applied Security Research, 12(1), 78-95. https://doi.org/10.1080/19361610.2017.1228026.

Strang, A., \& Ager, A. (2010). Refugee integration: Emerging trends and remaining agendas. International Migration Review, 23(4), 589-607. https://doi.org/10.1093/jrs/feq046.

Streitwieser, B., Loo, B., Ohorodnik, M., \& Jeong, J. (2018). Access for refugees into higher education: A review of interventions in North America and Europe. Journal of Studies in International Education, 21(2), 1-24. https://doi.org/10.1177/1028315318813201.

Swedish Council for Higher Education (Ed.). (2019). Studera.nu. Roads to studies. Information for asylum seekers.

Ulram, P. A. (2009). Integration in Österreich, Einstellungen, Orientierungen, und Erfahrungen von MigrantInnen und Angehörigen der Mehrheitsbevölkerung. Wien: GfK-Austria.

UNHCR (Ed.). (Ed.)(2017). DAFI annual report 2016. Geneva: UNHCR.

UNHCR. (2018). Flucht und Asyl in Österreich. Die häufigsten Fragen und Antworten. Wien: UNHCR-Büro in Österreich.

uniko. (2019). MORE—an initiative by uniko. https://uniko.ac.at/projekte/more/index.php?lang=EN. Accessed 24 July 2019.

Urry, J. (2000). Sociology beyond societies. London: Routledge.

Verwiebe, R., Kittel, B., Dellinger, F., Liebhart, C., Schiestl, D., Haindorfer, R., et al. (2018). Finding your way into employment against all odds? Successful job search of refugees in Austria. Journal of Ethnic and Migration Studies, 6(34), 1-18. https://doi.org/10.1080/1369183X.2018.1552826.

Publisher's note Springer Nature remains neutral with regard to jurisdictional claims in published maps and institutional affiliations. 